\title{
Comparative evaluation of dimensional stability and flexural strength of different light cured tray materials with self- cured tray material: an in-vitro study
}

\author{
Taha Attarwala', Ramandeep Dugal', Aamir Godil', Sanaa Wadwan', Pallavi Madanshetty², Arshi Kazi ${ }^{1}$ \\ ${ }^{1}$ M.A.Rangoonwala College of Dental Sciences and Research Centre, India, Department of Prosthodontics. \\ ${ }^{2}$ Rural Dental College, Pravara Institute of Medical Sciences, India, Department of Prosthodontics.
}

\section{Abstract}

Objectives: To carry out a comparative evaluation of dimensional stability and flexural strength of different light cured tray materials with self-cured tray material as control.

Materials and methods: The study was carried out in four groups based on the different available tray materials. Group A $(n=30)$ - light cured resin (Individo Lux-VOCO ${ }^{\text {TM }} \mathrm{GmbH}$ Germany); Group B ( $n=30$ )- light cured resin (Profibase-VOCO ${ }^{\mathrm{TM}} \mathrm{GmbH}$ Germany); Group C $(n=30)$ - light cured resin (Plaque Photo-Willmann and Pein ${ }^{\mathrm{TM}} \mathrm{GmbH}$ Germany); Group D $(n=30)$ - control group-self cured resin (Asian special instant tray material Asian Acrylates ${ }^{\mathrm{TM}}$, Mumbai, India). A digital micro-meter was used to measure the length of each specimen first at 1 hour, 24 hour and 48 hour and three readings were taken up to 0.001 decimal. The values for flexural strength of each specimen were measured using the 3-point bending technique with the help of a universal testing machine. The mean values of dimensional stability and flexural strength were calculated by the one-way ANOVA and Tukey's post-hoc test for multiple group's comparison.

Results The mean change in length (in $\mathrm{mm}$ ) of light cured resins samples were significantly lower than self-cured resin samples at all three time intervals. The flexural strength values of light cured resin samples-Group A $(84.46 \pm 13.32 \mathrm{~N} / \mathrm{mm} 2), B(83.43 \pm 14.52 \mathrm{~N} / \mathrm{mm} 2)$ and C $(86.80 \pm 14.73 \mathrm{~N} / \mathrm{mm} 2)$ was significantly higher than the self-cured resin samples group $D$
$(41.29 \pm 7.93 \mathrm{~N} / \mathrm{mm} 2)$ Conclusions: Light cured tray materials are more dimensionally stable and have a higher flexural strength compared to self-cured tray materials.

Keywords: Custom trays; light cured resins; dimensional stability; flexural strength.

Citation: Attarwala, T, et al. (2022) Comparative evaluation of dimensional stability and flexural strength of different light cured tray materials with self-cured tray material: an in-vitro study? 1:a001 doi:10.5195/d3000.2022.179

Received: April, 30, 2021

Accepted: July, 13, 2021

Published: March, 7, 2022

Copyright: (C2022 Attarwala, T, et al. This is an open access article licensed under a Creative Commons Attribution Work 4.0 United States License.

Email: tahaattarwala@gmail.com 
Comparative evaluation of dimensional stability and flexural strength of different light cured tray materials with self-cured tray material: an in-vitro study

\section{Introduction}

A dimensionally accurate impression is of primary importance for a precise fitting dental prosthesis. According to the Glossary of Prosthodontic Terms9, a custom tray is defined as "an individualized impression tray made from a cast recovered from a preliminary impression. It is used in making a final impression.1-2 Ideal requirements for a custom tray material are that it must have dimensional and volumetric stability in air and in a moist environment over a period of time, good rigidity (high modulus of elasticity), the impression material must adequately adhere to the tray and should control the thickness of layer of impression material. 3

Several materials are available commercially for the construction of custom trays such as poly methyl methacrylate (PMMA), shellac, thermoform sheets, light cured acrylic resin, polycaprolactone materials and printable thermoplastic resins. Shellac was a popular tray and temporary denture base material in the twentieth century. However, Basker et al (1976) and Wilson et al (1987) reported that it is brittle, breaks easily and is difficult to trim and make the periphery smooth and future heating is likely to cause distortion. Its use as a special tray material was discontinued as poly methyl methacrylate gained popularity. 4

Chemically cured (CC) / autopolymerising PMMA resin is used most commonly for the fabrication of custom trays due to its convenience, cost efficiency, ready availability and favourable mechanical properties5. However, acrylic resins have also shown to be cytotoxic as a result of substances that leach from the resin. The primary cause is residual monomer, resulting from incomplete conversion of monomers into polymer; which has the potential to cause irritation, inflammation and an allergic response of the oral mucosa6. A residual monomer content of about $2-6 \%$ has been reported in self-cured resins. Despite the fact that poly methyl methacrylate has low solubility in water, remaining monomer may spread into the oral mucosa. Various researches have shown that the volumetric shrinkage of chemically cured resins is $7 \%$, along with this there is also some linear shrinkage which affects the dimensional stability. These resins also absorb water slowly over a period of time, which acts as a plasticizer further affecting their dimensional stability. 3
The flexural strength of acrylic resins depend on numerous factors such as polymer molecular weight and bead size, residual monomer level, plasticizer composition, cross-linking agent, internal porosity of the polymer matrix and action of chemical agents. One drawback of PMMA resins during clinical service is its ability to fracture, especially when large undercuts are present and any type of fracture is a time consuming and costly problem besides being inconvenient for patients and clinicians.7

Taking into consideration all the drawbacks related to PMMA resins, several newer light cured resins were introduced in the early 1980s and emerged as one of the promising materials for custom tray fabrication in removable and fixed prosthodontics. The lightcuring resin is composed of urethane dimethacrylate (UDMA) matrix and a small amount of silica which adjusts flow characteristics of this material8. Although they are in routine use in current clinical practice, their physical properties and dimensional accuracy are not sufficiently reported in current literature.

Hence, in the present study, the dimensional stability of three different commercially available light cured tray materials was 
evaluated at 1 hour, 24 hour and 48 hour time intervals and compared to self-cured tray material which was taken as the control. Moreover, since custom trays should exhibit an adequate stiffness and fracture resistance in all clinical situations; flexural strength was also evaluated for these materials.

The null hypothesis of this study is that there is no difference between the dimensional stability and flexural strength of the test light cure and autopolymerising custom tray materials. The alternate hypothesis is that light cure tray materials have better dimensional stability and flexural strength as compared to autopolymerising custom tray materials.

\section{Material and Methods}

The study was divided into four groups as follows:

Group A- Light cured resin (Individo Lux-VOCO ${ }^{\text {TM }} \mathrm{GmbH}$ Germany) / Group B - Light cured resin (Profibase-VOCO ${ }^{\mathrm{TM}} \mathrm{GmbH}$ Germany) / Group C - Light cured resin (Plaque Photo-Willmann and Pein ${ }^{\text {TM }}$ GmbH Germany) / Group D - Self cured resin (Asian special instant tray material Asian Acrylates $^{\mathrm{TM}}$, Mumbai, India)

1. Fabrication of template:
A perspex sheet was used to prepare the template by laser cutting and engraving using RDWorks V7 software. The customised template was designed in the desired dimensions of $2 \mathrm{~mm}$ thickness, $20 \mathrm{~mm}$ length and $4 \mathrm{~mm}$ width according to the guidelines of the American Society of Testing Materials ${ }^{3}$. This planning was then transferred to a laser cutting machine $\left(\mathrm{CO}_{2}\right.$ laser, Trilok Lasers Pune, India). The templates were laser cut with $5 \mathrm{~mm}$ extra space on each side. The cover of the template was made by placing an uncut perspex sheet on top of the accurately prepared template. A total of 60 templates were prepared. The sample size was determined by Power analysis with a confidence interval of $95 \%$ and $p$ value $<0.05$ was considered as statistically significant.

2. Fabrication of light cured and self-cured specimens:

A thin layer of petroleum jelly was applied on the customised template as a separating medium prior to preparation of specimens. A sheet of light cured tray material was cut and adapted into the template. The entire assembly was then placed into a light curing unitbre. LUX Power unit 2 at $230 \mathrm{~V}, 50$ $\mathrm{HZ}$ and $28 \mathrm{~W}$ and was allowed to cure for 3 minutes. Once set, the template was disassembled and the specimens of the desired

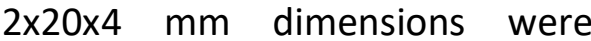
retrieved. The specimens were then separately placed back into the light curing unit for an additional 3 minutes to allow complete polymerization of the material. The specimens were checked for any irregularities and discrepancies or errors in dimensions and those with visible defects were discarded and replaced. The specimens were stored in a dry environment (Figure $1)$.

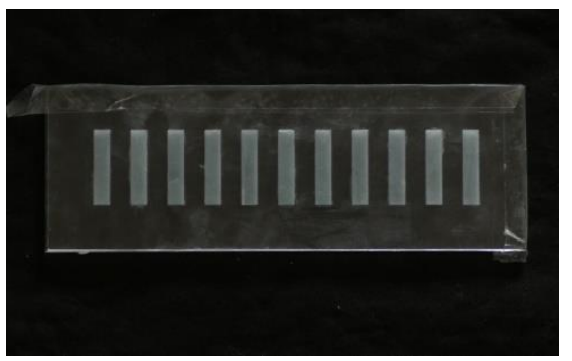

Fig 1: Preparation of samples using perspex template

Similarly, the self-cured specimens were prepared by mixing the polymer and monomer according to the manufacturer's instructions (3:1 v/v or $2.5: 1 \mathrm{w} / \mathrm{w})$ in a silicon cup and added to the Perspex template. The specimens were retrieved after complete polymerization and stored in a dry environment.

Total number of specimens prepared in the study (sample size): 
15 specimens were prepared for each group for measuring dimensional stability $(n=60)$ and 15 specimens for each group for measuring flexural strength $(n=60)$.

\section{Testing of specimens:}

a. Dimensional stability:

Dimensional stability of prepared samples was evaluated at 1 hour, 24 hours and 48 hours respectively. A digital micro-meter was used to measure the length of each specimen first at 1 hour and three readings were taken up to 0.001 decimal. The same procedure was followed at 24 hours and 48 hours respectively. Average of the three readings was made and this average was subtracted from the initial length of $20 \mathrm{~mm}$ to determine change in length and get the dimensional stability at 1,24 and 48 hours respectively.

Change in length $\Delta I=I_{1}-I_{2}$

$\mathrm{I}_{1}=$ initial length

$\mathrm{I}_{2}=$ measured length

b. Flexural strength:

Specimens were subjected to a single compressive load using the 3-point bending technique with the help of a universal testing machine, Star Testing System, India. Model no. STS-248

Accuracy of machine $\pm 1 \%$, cross head speed $0.5 \mathrm{~mm} / \mathrm{min}$. (Figure 2)
Comparative evaluation of dimensional stability and flexural strength of different light cured tray materials with self-cured tray material: an in-vitro study

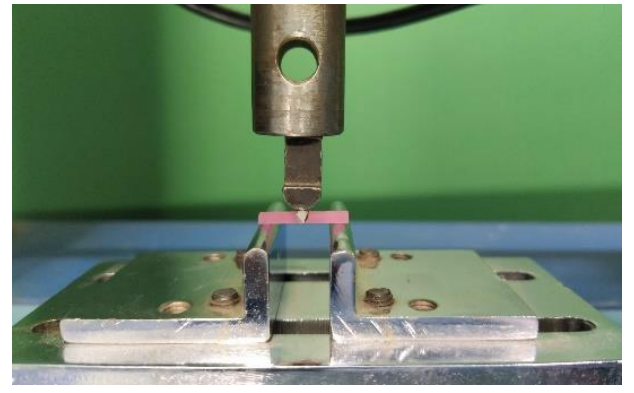

Fig 2: Measurement of flexural strength using universal testing machine

A centrally located load was applied until the specimens fractured. The maximum force (in N) was recorded and presented by software program attached to the universal testing machine. This maximum force was used to calculate the Flexural strength in $\mathrm{MPa}$ using the following formula:

$$
\begin{aligned}
& F S=\frac{3 F L}{2 d^{2}} \\
& F=\text { the maximum force } \\
& \text { registered during testing } \\
& L=\text { length of the support } \\
& \text { span } \\
& b=\text { width of specimen } \\
& d=\text { thickness of specimen }
\end{aligned}
$$

\section{Results}

A total of 60 specimens were prepared and evaluated for dimensional stability and flexural strength. (15 samples per group for each test)

The inter group comparison of dimensional stability between each of the four test groups was done by ANOVA with Tukey's post-hoc test for multiple groups comparison. All $p$ values< 0.05 were considered statistically significant. The mean change in length $(\mathrm{mm})$ for Group A $(0.09 \pm 0.026), B(0.09 \pm 0.028)$ and $C$ $(0.09 \pm 0.026)$ was noted to be significantly lower than group $D$ $(0.39 \pm 0.035)$ at time interval of $1 \mathrm{hr}$. Similarly for the time interval of 24 hours-Group A (0.11 \pm 0.02$)$, B $(0.10 \pm 0.02)$ and $C(0.10 \pm 0.02)$ was significantly lower than group $D$ (0.43 \pm 0.03$)$. As well as for 48 hour interval- Group A $(0.12 \pm 0.02)$, B $(0.11 \pm 0.01)$ and $C(0.12 \pm 0.02)$ was significantly lower than group $D$ (0.44 \pm 0.03$)$.

The inter group comparison of flexural strength between each of the four test groups was done by ANOVA with Tukey's post-hoc test for multiple groups comparison. The $p$-value corresponding to the F-statistic of one-way ANOVA is lower than 0.05 , suggesting that the one or more treatments are significantly different. The mean flexural strength of Group $A$ $\left(84.46 \pm 13.32 \mathrm{~N} / \mathrm{mm}^{2}\right), \quad B$ $\left(83.43 \pm 14.52 \mathrm{~N} / \mathrm{mm}^{2}\right)$ and $\mathrm{C}$ $\left(86.80 \pm 14.73 \mathrm{~N} / \mathrm{mm}^{2}\right)$ was noted to be significantly higher compared to group D $\left(41.29 \pm 7.93 \quad \mathrm{~N} / \mathrm{mm}^{2}\right)$ (Tables 1.1 and 1.2) 
Vol 10 No 1 (2022) DOI 10.5195/d3000.2022.179

Table 1.1: Inter group comparison of the four test groups with respect to the flexural strength in $\mathrm{N} / \mathrm{mm}^{2}$ :

\begin{tabular}{|c|c|c|}
\hline Groups & Mean $\left(\mathbf{N} / \mathbf{m m}^{\mathbf{2}}\right.$ ) & Standard Deviation \\
\hline Individo Lux (Group A) & 84.46 & 13.12 \\
\hline Profibase (Group B) & 83.43 & 14.52 \\
\hline Plaque Photo (Group C) & 86.80 & 14.73 \\
\hline Self-cure (Group D) & & \\
\hline
\end{tabular}

Table 1.2: Tukey HSD Test:

\begin{tabular}{|c|c|c|c|c|}
\hline Product & Difference & $\begin{array}{l}\text { 95\% Confidence Interval } \\
\text { (Upper and lower limits) }\end{array}$ & $p$ value & Inference \\
\hline$A$ vs $C$ & 2.34 & -10.10 to 14.78 & 0.95 & Not significant \\
\hline$A$ vs $B$ & 1.03 & -13.47 to 11.41 & 0.99 & Not significant \\
\hline$A$ vs $D$ & -43.17 & -55.61 to -30.72 & 0.000 & $\begin{array}{c}\text { The mean of self-cure was } \\
\text { significantly lower }\end{array}$ \\
\hline C vs $B$ & -3.37 & -15.81 to 9.07 & 0.88 & Not significant \\
\hline C vs D & -45.51 & -57.95 to -33.06 & 0.0000 & $\begin{array}{c}\text { The mean of self-cure was } \\
\text { significantly lower }\end{array}$ \\
\hline$B$ vs $D$ & -42.14 & -54.58 to -29.69 & 0.0000 & $\begin{array}{c}\text { The mean of self-cure was } \\
\text { significantly lower }\end{array}$ \\
\hline
\end{tabular}


Comparative evaluation of dimensional stability and flexural strength of different light cured tray materials with self-cured tray material: an in-vitro study

Vol 10 No 1 (2022) DOI 10.5195/d3000.2022.179

\section{Discussion}

The null hypothesis is not accepted as there is a difference between the dimensional stability and flexural strength of the test light cure and autopolymerising custom tray materials. Accuracy of an impression is the fundamental aspect of prosthodontic therapy. Numerous factors governing the precision of these impressions and subsequent casts include: type of impression trays, correct manipulation of impression materials, the method used to make the impression, the materials used for making casts and proper time of cast fabrication. Among the enlisted factors, the type of impression tray used plays a significant role in the fit of the final prosthesis. ${ }^{8-9}$

Custom trays and stock trays have been widely used for making dental impressions.

Thonthammact et al ${ }^{9}$ noted that accurate casts can be made with either stock or custom trays. However, using a custom tray represents a dentist's best efforts to obtain exact replication of the teeth and tissues. It exemplifies rigidity and uniform thickness of the impression material as recommended by several other authors. Therefore, any materials used to make custom trays must be dimensionally stable over time.

Autopolymerising acrylic resins have been used for the fabrication of custom trays, but concerns about the exposure of dental personnel to acrylic resin monomer have been expressed. Distortion from polymerization shrinkage and residual stress relaxation makes them a less than ideal material for custom trays. Research has suggested that custom trays should be fabricated at least 24 hours before impressions are made, although some investigators have suggested different periods (40 minutes to 9 hours) between making resin trays and using them, to allow the material to become relatively dimensionally stable. ${ }^{10} \mathrm{Hamza}$ et al ${ }^{11}$ found that autopolymerising resin continues to shrink, with significant dimensional change occurring for up to 180 days.

Light cured resins have gained popularity as a custom tray material in the past few years and hence has been the centre of research question in this study. Several studies have focussed on the properties of the light cured resins and numerous advantages have been identified when compared to the self-cured resins, such as lack of offensive odour; improved working time; excellent dimensional and volume stability; sufficient rigidity and stiffness; ease of manipulation and the immersion in disinfectants with no effect on the physical or mechanical properties of this material. ${ }^{9}$ Its disadvantages include needs a special light-curing unit, and difficulty in trimming and finishing.

A perspex template was constructed and used for the fabrication of the specimens of equal dimensions. ${ }^{11}$ This is preferred to machining the specimens since it has been reported by Neihart et al ${ }^{12}$ that grinding may weaken the specimen by creating multiple cracks and surface irregularities which can initiate the fracture process. Specimens can be fabricated using a metal, plastic or perspex template. Since, in the present study the specimens had to be placed in a light-curing unit for polymerization, a light transmitting template was required. Thus, in this study, perspex material was used to prepare the template.

When fabricating self-cured specimens, correct powder and liquid ratios must be adhered to decrease any source of error. The ratio of powder to liquid (3:1 v/v or $2.5: 1 \mathrm{w} / \mathrm{w}$ ) by measurement as 
instructed by manufacturers was used. However, this presented a relative technique sensitive as well as time consuming step as the specimens fabricated without adhering to the recommended powder to liquid ratio would result in them becoming dry and brittle. The light cured materials on the other hand was less technique sensitive to fabricate as it comes in a wafer of uniform thickness and can be cut to desired size until cured in the polymerisation unit. In this study, the change in length of the four study groups was measured at 1, 24 and 48 hours respectively with the help of a digital micro-meter, since it is accurate, easy to use and readily available.

The inter group comparison of change in length between each of the four groups at the three time intervals was done by ANOVA with post-hoc test (Tukey HSD) for multiple groups comparison. The light cure materials displayed greater dimensional stability at all three time intervals compared to the self-cure material (Table 2.1). Between the light cured materials, there was no significant difference in the dimensional stability at all three intervals which is in accordance with the studies conducted by Breeding et $\mathrm{al}^{13}$ and Wirz et al ${ }^{14}$.

Table 2.1: Inter group comparison of change in length of the four test groups at different intervals:

\begin{tabular}{|c|c|c|c|c|c|c|c|c|c|c|c|c|}
\hline \multirow{2}{*}{$\begin{array}{c}\text { Treatment } \\
\text { Interval }\end{array}$} & \multicolumn{3}{|c|}{$\begin{array}{l}\text { Individo Lux } \\
\text { (Group A) } \\
\quad(n=15)\end{array}$} & \multicolumn{3}{|c|}{$\begin{array}{l}\text { Profibase } \\
\text { (Group B) } \\
(n=15)\end{array}$} & \multicolumn{3}{|c|}{$\begin{array}{l}\text { Plaque Photo } \\
\text { (Group C) } \\
(n=15)\end{array}$} & \multicolumn{3}{|c|}{$\begin{array}{l}\text { Self-cure } \\
\text { (Group D) } \\
(n=15)\end{array}$} \\
\hline & $1 \mathrm{~h}$ & $24 \mathrm{~h}$ & $48 \mathrm{~h}$ & $1 \mathrm{~h}$ & $24 \mathrm{~h}$ & $48 \mathrm{~h}$ & 1h & $24 \mathrm{~h}$ & $48 \mathrm{~h}$ & $1 \mathrm{~h}$ & $24 \mathrm{~h}$ & $48 \mathrm{~h}$ \\
\hline $\begin{array}{l}\text { Mean change in } \\
\text { length }(\mathrm{mm})\end{array}$ & 0.09 & 0.11 & 0.12 & 0.09 & 0.10 & 0.11 & 0.09 & 0.10 & 0.12 & 0.39 & 0.43 & 0.44 \\
\hline Sample SD & 0.026 & 0.02 & 0.02 & 0.028 & 0.02 & 0.01 & 0.026 & 0.02 & 0.02 & 0.035 & 0.03 & 0.03 \\
\hline
\end{tabular}


Comparative evaluation of dimensional stability and flexural strength

Intra group comparison (Table 2.2) showed that the light cured groups $A$ and $B$ did not show any significant difference in the three time intervals whereas group $C$ showed a statistical difference between 1 and 48 hour time interval. For group D - The mean change in length of the samples after 1 hour $(0.39 \pm 0.03 \mathrm{~mm})$ was significantly lower as compared to after 24 hours $(0.43 \pm 0.03 \mathrm{~mm})$ and 48 hours $(0.44 \pm 0.03 \mathrm{~mm})$ respectively. No difference in the mean change in length between $24(0.43 \pm 0.03 \mathrm{~mm})$ and 48 hours $(0.44 \pm 0.03 \mathrm{~mm})$ was seen.

These results show that the self-cured resins when being kept in a dry environment undergo dimensional changes up to 24 hours and thus must be stored for at least 24 hours before they become dimensionally stable. Thus a waiting period may be recommended between fabrication and use of the tray clinically. This is in agreement with various studies by Wirz et $\mathrm{al}^{14}$, Rueda et $\mathrm{al}^{15}$, Burton et $\mathrm{al}^{16}$ and Anderson et $\mathrm{al}^{17}$.

Custom tray materials also must not permanently deform during the impression making procedure when the filled custom tray is inserted intra orally or as the completed impression is retrieved from the oral cavity. ${ }^{14}$ The tray materials should be able to withstand and resist the force required to remove a completed impression from the oral cavity and the resulting internal stresses. The mean of flexural strength value of Group A $\left(84.46 \pm 13.32 \mathrm{~N} / \mathrm{mm}^{2}\right)$ was significantly higher compared to Group D $\left(41.29 \pm 7.93 \mathrm{~N} / \mathrm{mm}^{2}\right)$. Similarly mean flexural strength of Group B $\left(83.43 \pm 14.52 \mathrm{~N} / \mathrm{mm}^{2}\right)$ and Group C (86.80 \pm 14.73 $\mathrm{N} / \mathrm{mm}^{2}$ ) were significantly higher as compared to the control Group D $\left(41.29 \pm 7.93 \mathrm{~N} / \mathrm{mm}^{2}\right)$. The lower flexural strength values of the self-cured resins may be due to the presence of residual monomer (2-6\%) and a lesser interpenetrating polymer network due to its short curing time which could affect the strength.
Table 2.2: Intra group comparison of change in length of the four test groups at different intervals using Tukey HSD Test:

\begin{tabular}{|c|c|c|c|}
\hline Treatment pair & \multicolumn{3}{|c|}{ Tukey HSD (p-value) } \\
\hline & 1 h & $\mathbf{2 4 h}$ & $\mathbf{4 8 h}$ \\
\hline A vs B & 0.86 & 0.89 & 0.84 \\
\hline A vs C & 0.89 & 0.67 & 0.89 \\
\hline A vs D & $\mathbf{0 . 0 0 1}$ & $\mathbf{0 . 0 0 1}$ & $\mathbf{0 . 0 0 1}$ \\
\hline B vs C & 0.89 & 0.89 & 0.88 \\
\hline B vs D & $\mathbf{0 . 0 0 1}$ & $\mathbf{0 . 0 0 1}$ & $\mathbf{0 . 0 0 1}$ \\
\hline C vs D & $\mathbf{0 . 0 0 1}$ & $\mathbf{0 . 0 0 1}$ & $\mathbf{0 . 0 0 1}$ \\
\hline
\end{tabular}

The light cured tray materials may exhibit a higher fracture resistance and can withstand higher forces due to cross-linking agents though this cannot be emphatically stated.

The extreme hardness has been labelled a disadvantage by Smith et al $^{18}$ as it makes it more difficult to grind. Khan and Greets ${ }^{3}$ reported that the light cured tray materials have a significantly higher resistance against bending as compared to the selfcured material. In the present study, among the light cured groups, Plaque Photo ${ }^{\mathrm{TM}}$ (Group C) showed the highest flexural strength values $\left(86.80 \pm 14.73 \mathrm{~N} / \mathrm{mm}^{2}\right)$, it may be partly attributed to the filler particle size and volume fraction. Flexural strength values may also be affected by the curing light intensity, time of curing and temperature. 
Use of light cured materials as a routine custom tray material can be advocated not only due to them exhibiting acceptable strength and dimensional stability over the conventional and routinely used self-cured materials, but also due to the relative absence of any unreacted monomer after their polymerisation and their ease of manipulation. Therefore, the use of light cured tray materials can be recommended over autopolymerising resins for fabrication of custom trays in routine clinical practice.

\section{Limitations of the study}

In-vitro nature of the study

The samples do not replicate the exact shape and anatomy of the custom tray.

\section{Conclusions}

Within the limitations of the study, the following conclusions were derived:

A) The three different light cured tray materials showed better dimensional stability compared to the self-cured tray material at all the three time intervals of 1 hour, 24 hours and 48 hours respectively. Between the light cured materials, Plaque Photo ${ }^{\mathrm{TM}}$ (Group C) showed a significant difference in dimensional stability between the 1 hour and 48 hour time interval.

B) The three light cured tray materials showed greater flexural strength as compared to the selfcured tray material. Between the light cured materials, Plaque Photo $^{\text {TM }}$ (Group C) showed the highest flexural strength, however it was not statistically significant when compared to Individo Lux ${ }^{\mathrm{TM}}$ (Group A) and Profibase ${ }^{\mathrm{TM}}$ (Group B).

This highlights that the light cured tray materials are suitable custom tray materials and provide a viable alternative to the self-cured material. These results, should however be validated in in-vivo conditions before clinical use.

\section{Competing interests}

The authors declare that they have no competing interests.

\section{References}

1. Payne JA, Pereira BP. Bond strength of three nonaqueous elastomeric impression materials to a light-activated resin tray. International Journal of Prosthodontics. 1992 Jan 1;5(1).PMID: 1520444

2. Ferro KJ, Morgano SM, Driscoll CF, Freilich MA, Guckes AD,
Knoernschild KL, McGarry TJ, Twain M. The Glossary of Prosthodontic Terms.

3. Khan SB, Geerts G. Determining the dimensional stability, fracture toughness and flexural strength of light-cured acrylic resin custom tray material. European Journal of Prosthodontics and Restorative Dentistry. 2009 Jun 1;17(2):67. PMID: 19645307

4. Azouka A, Huggett $R$, Harrison $A$. The production of shellac and its general and dental uses: a review. J Oral Rehabil. 1993 Jul;20(4):393-400. https://doi.org/10.1111/j.1365-

\subsection{3.tb01623.x}

5. Pagniano RP, Scheid RC, Clowson RL, Dagefoerde RO, Zardiackas LD. Linear dimensional change of acrylic resins used in the fabrication of custom trays. Journal of Prosthetic Dentistry. 1982 Mar 1;47(3):279-83.

https://doi.org/10.1016/00223913(82)90157-3

6. Jorge JH, Giampaolo ET, Machado AL, Vergani CE. Cytotoxicity of denture base acrylic resins: a literature review. J. Prosthet. Dent. 2003 Aug 1;90(2):190-3.

https://doi.org/10.1016/S00223913(03)00349-4

7. Asli HN, Moradian S, Asli MN. Comparison of transverse 
strength of three different types of heat cured resin acrylics. Biosci Biotechnol Res Commu. 2017 Apr $1 ; 10(2): 248-51$.

8. Scott A, Egner W, Gawkrodger DJ, Hatton PV, Sherriff M, Van Noort R, Yeoman C, Grummitt J. The national survey of adverse reactions to dental materials in the UK: a preliminary study by the UK Adverse Reactions Reporting Project. British Dental Journal. 2004 Apr;196(8):471.

https://doi.org/10.1038/sj.bdj.481 1176

9. Thongthammachat S, properties. J. Prosthet. Dent. 1994 Moore BK, Barco MT, Hovijitra $S$, Brown DT, Andres CJ. Dimensional accuracy of dental casts: influence of tray material, impression material, and time. Journal of Prosthodontics. 2002 Jun;11(2):98108.

https://doi.org/10.1053/jopr.2002 .125192

10. Valderhaug J, Fløystrand F. Dimensional stability of elastomeric impression materials in custom-made and stock trays. J. Prosthet. Dent. 1984 Oct 1;52(4):514-7.

https://doi.org/10.1016/0022-

3913(84)90336-6

11. Hamza TA, Rosenstiel SF, Elhosary MM, Ibraheem RM. The effect of fiber reinforcement on the fracture toughness and flexural strength of provisional restorative resins. J. Prosthet. Dent. 2004 Mar 1;91(3):258-64.

https://doi.org/10.1016/j.prosden t.2004.01.005

12. Neihart TR, Li SH, Flinton RJ. Measuring fracture toughness of high-impact poly (methyl methacrylate) with the short rod method. J. Prosthet. Dent. 1988 Aug 1;60(2):249-53.

https://doi.org/10.1016/00223913(88)90325-3

13. Breeding LC, Dixon DL, Moseley JP. Custom impression trays: Part I-Mechanical Jan 1;71(1):31-4.

https://doi.org/10.1016/0022-

3913(94)90252-6

14. Wirz J, Jaeger K, Schmidli F. Light-polymerized materials for custom impression trays. International Journal of Prosthodontics. 1990 Jan 1;3(1).PMID: 2196894

15. Rueda L, Sy-Muñoz JT, Naylor WP, Goodacre CJ, Swartz ML. The effect of using custom or stock trays on the accuracy of gypsum casts. International Journal of Prosthodontics. $1996 \mathrm{Jul}$ 1;9(4).PMID: 8957875

16. Burton JF, Hood JA, Plunkett DJ, Johnson SS. The effects of disposable and custommade impression trays on the accuracy of impressions.
Journal of dentistry. 1989 Jun 1;17(3):121-3. https://doi.org/10.1016/03005712(89)90104-8

17. Anderson GC, Schulte JK, Arnold TG. Dimensional stability of injection and conventional processing of denture base acrylic resin. Journal of Prosthetic Dentistry. 1988 Sep 1;60(3):394-8. https://doi.org/10.1016/00223913(88)90292-2

18. Smith PW, Richmond R, McCord JF. Prosthodontics: The design and use of special trays in prosthodontics: guidelines to improve clinical effectiveness. $\mathrm{Br}$ Dent J. 1999 Oct;187(8):423. https://doi.org/10.1038/sj.bdj.480 0295 